\title{
AN ANALYTICAL STUDY TO ASSESS FOOD SUBSIDY SYSTEM IN FAYOUM GOVERNORATE
}

\author{
TOLBA , A. SAADAWI ${ }^{1}$, O. M. MOHAMED ${ }^{2}$, SH. A. ABD EL AZIZ ${ }^{3}$ \\ and G. A. ABO ELELA ABD ELBAKI ${ }^{3}$
}

\author{
1. Research For The Strategic Studies Institute Of The Nile Basin Countries - Fayoum \\ University \\ 2. Rural Social. Faculty Of Agriculture. Fayoum University. \\ 3. Agricultural Economics Research Institute . ARC.
}

(Manuscript received 27 November 2016)

\begin{abstract}
$\mathrm{R}$ esults of the study showed that about $95 \%$ of the study sample is not sufficient amount of support due Everyone restricted ration cards and therefore inadequate food commodities. results also showed that about $29 \%$ of the study sample face difficulties in exchange courses ration due to the late arrival of the decisions of the ration and non-availability of courses in full each month and the inadequacy of goods and lack of diversity and exchange courses twice a month and severe overcrowding. and approved about $35 \%$ of respondents said the transition to monetary support and suggested monthly payments ranged between 40-160 pounds per person. the study found that about $60 \%$ of the study sample were unhappy with subsidies ration system members. The assessment of the contribution rate of food commodities and supported in the coverage of the needs of the beneficiary families food support (bread - Sugar - oil - Rice) show that the: The average proportion of family members of the subsidized bread benefit amounted to about $105 \%$ of the total consumption of bread. which there is a surplus in the subsidized bread than the needs of individuals by about $5 \%$. As it turns out that the average proportion of family members benefit from the subsidized sugar amounted to about $51 \%$ of the total consumption of sugar. It also turns out that the average proportion of family members benefit from the subsidized oil amounted to about $46 \%$ of the total consumption of oil. It also turns out that the average proportion of family members benefit from the subsidized rice amounted to about $31 \%$ of the total consumption of rice and turns of the linear model that the most influential factor to take advantage of subsidized rice is the variable age.
\end{abstract}




\title{
تقييم منظومة الدعم الغذائي في محافظة الفيوم
}

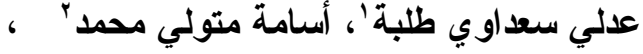

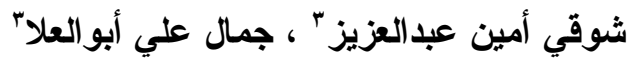

$$
\begin{aligned}
& \text { 1- معهز البحوث والدراسات الاستر اتيجية لدول حوض النيل - جامعة الفيوم. } \\
& \text { r- المجتمع الريفي - كلية الزراعة - جامعة الفيوم. } \\
& \text { r- معهز بحوث الاقتصاد الزراعي - مركز البحوث الزراعية. }
\end{aligned}
$$

يمثل الدعم الغذائي أحد أهم السياسات الاقتصادية في مصر، ومن أهم أهدافه المعلنة التوزيع العادل للسلع الغذائية المدعمة للحفاظ على حد أدنى لمستوى المعيشة للمواطنين في الدول النامية، و التخفيف من حدة المشكلة الاقتصادية و الاجتماعية التي ترتبط بارتفاع معدلات الأسعار و الفقر و انخفاض مستوى المعيشة ونظر اً لارتفاع عدد السكان الذين يعيشون تحت خطي (') الفقر المدقع و الفقر

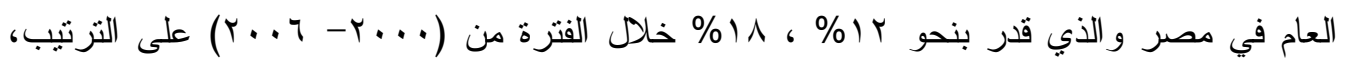

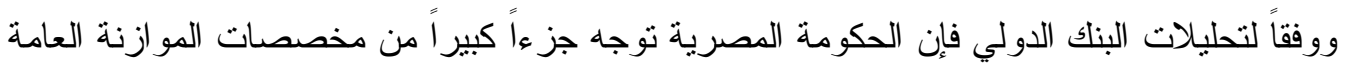

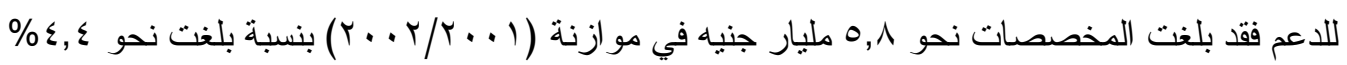

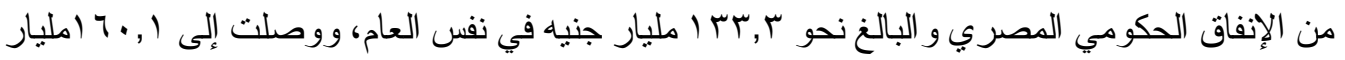

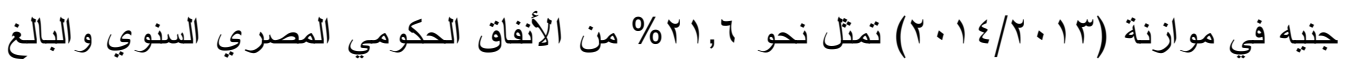

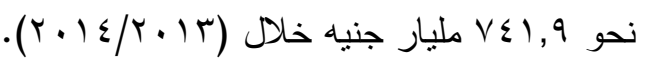

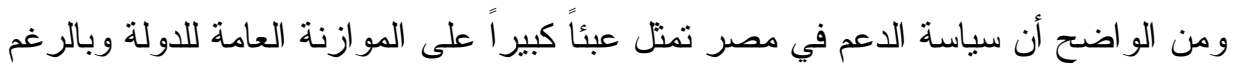

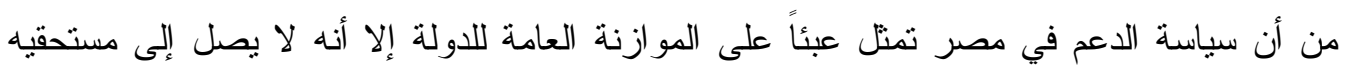

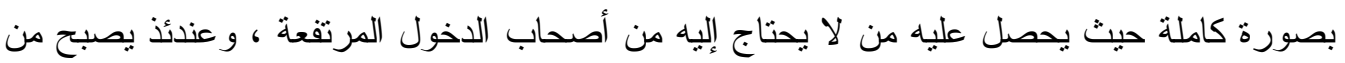
الإنصاف أن يعاد مرة أخرى نوصيف الدعم وفقاً لأولوية من بيتحق ومن لا لا يستحق حتى يمكن وصول الدعم إلى مستحقيه الفعليين.

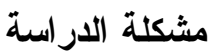

بالرغم من جهود الحكومة الحثيثة لـ ضمان ا ستمر ارية الدعم الغذائي ومحاولة تطويره. تتعدد المشكلات التي تواجه تلك الجهود وتتمنل أهم مشكلات نظام الدعم الغذائي في مصرفي الأتي: 1- عدم كفاية السلع المدعمة للحاجات الفعلية للمو اطنين محدودي الاخل. r- عدم اســتهداف الفقر اء فقط بالدعم وحصـــول نســبة كبيرة من الأغنياء على معظم الدعم حيث يتسرب الدعم إلى غير مستحقيه و لا يصل إلى ذسبة غير قليلة من السكان ممن يستحقون الدعم

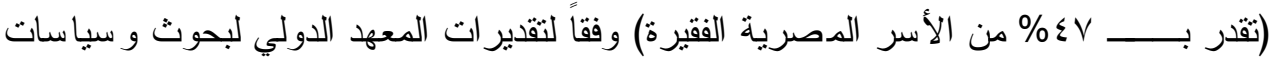

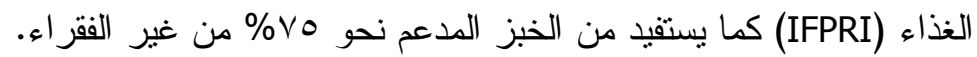


ب- عدم القدرة على سد الفجوة الغذائية على نحو يـ ستدعى الاستير اد من الخارج بصورة عرّ ضت

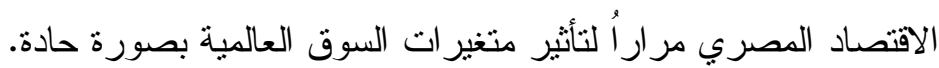

ع- انخفاض جودة الخبز البلدي المدعم، و السلع الغذائية المدعمة.

$$
\text { أهداف الدر اسة }
$$

تستهدف الدر اسة بصفة أساسية تقييم منظومة الدعم الغذائي في الفيوم و التعرف على مدى الفى

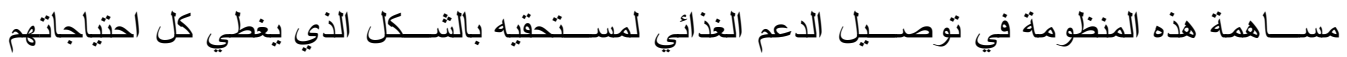
الأســــــية بفاعليه وبالجودة الملائمة مع مر اعاة تفضـــلاتهم المختلفة ويتم تحقيق هذا الهدف وفقا

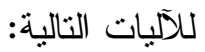

$$
\text { ا - توصيف الو اقع الر اهن للاعم الغذائي في مصر . }
$$

r r دراسة بعض القضايا المتعلقة بمنظومة الدعم الغذائي.

ب- التعرف على مد ساهمة الـ سلع الغذائية المدعمة في تغطية احتياجات الأسر الد ستهدفة بالدعم في ظل تطبيق المنظومة الجديدة للاعم الغذائي. ؛ - التعرف على أهم الم شكلات التي تواجه سيا سة الدعم الغذائي وأهم المقترحات اللازمة لعلاج هذه المشكلات.

\section{الطريقة البحثية ومصادر البياتات}

تعتمد الدراسة على أسلوب التحليل الو صفي و الكمي و على المؤشرات الإحصائية وأساليب المعاينة الميدانية وتعتمد الدر اسة على مصدرين للبيانات هما البيانات الثانوية و البيانات الأولية. 1- البيانات الثانوية:

هي البيانات المذ شورة وغير المذ شورة من خلال عدة هـ صادر هي وزارة التموين، وموقع الهُ

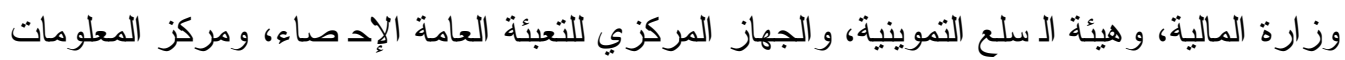

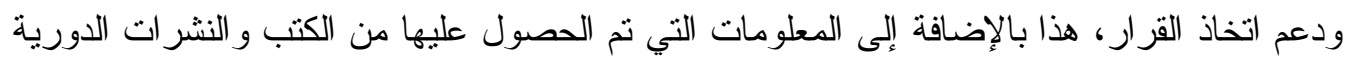

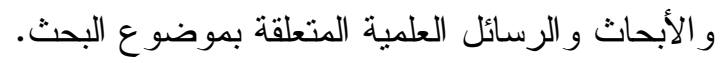

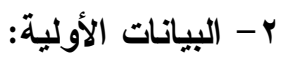
تم الد صول عليها من خلال عينة ميدانية من ح ضر وريف محافظة الفيوم حيث تم اختيار حي الثيخ حسن بيندر الفيوم ليمنل الدضر وقريتي قصر الباسل وابو صير دفنو بمركز اطسا لتمثل ونل الريف عن طريق استخدام استمارة استبيان بأسلوب المقابلة الشخصية مع أفراد العينة خلال الفترة

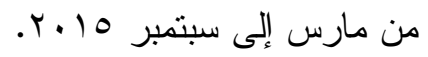

\section{نتائج الار اسة}

1- تطور قيمة الدعم ونسبته من الإنفاق العام والناتج المحلي الإجمالي:

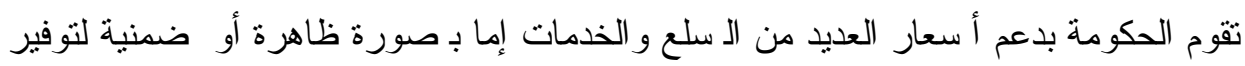

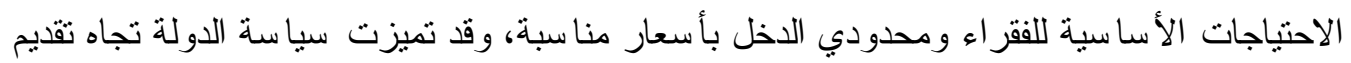

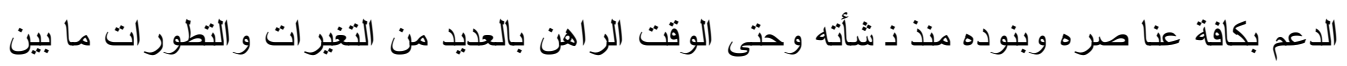

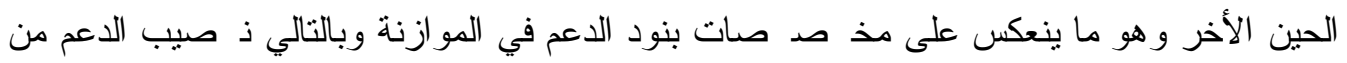


إجمالي الإنفاق الحكومي حيث اختلف نصـــيب الدعم في الموازنة العامة للاولة تاريخيا على مدار الـ سنوات الما ضية ، يو ضح الجدول رقم (1) تطور ذـ سبة الدعم من الإنفاق العام و الناتج المحلي

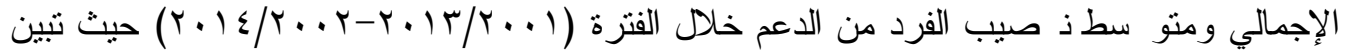

زيادة قيمة الدعم من 0,1 مليار جنيه بما يعادل نحو ؟,؛ \% من إجمالي الإنفاق العام ، 0,1\% من

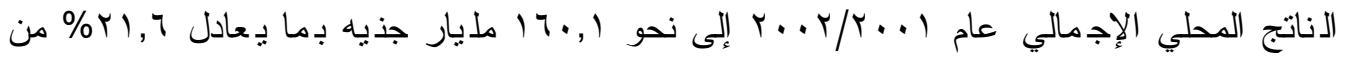

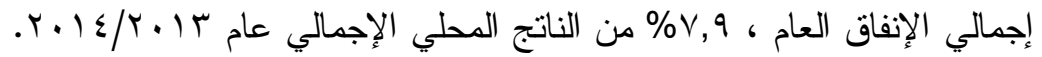

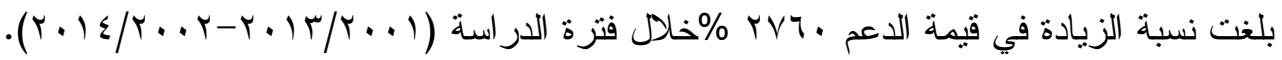

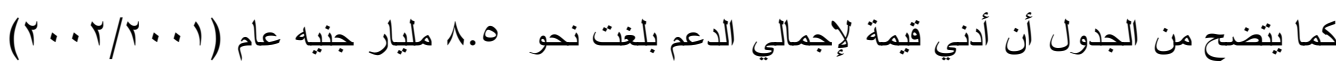

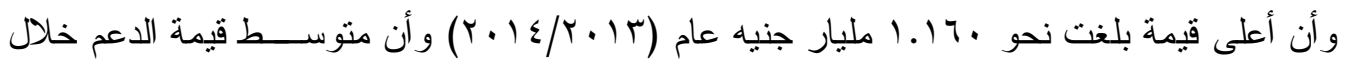

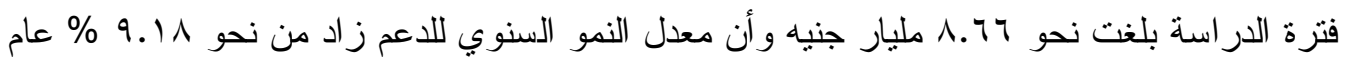

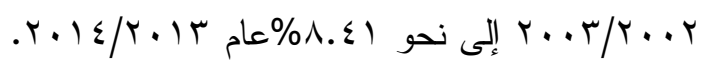
جدول رقم (1) تطور نسبة الدعم من الإنفاق العام و الناتج المحلي الإجمالي

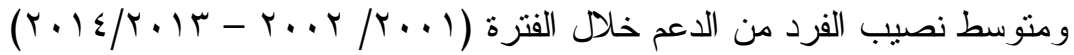

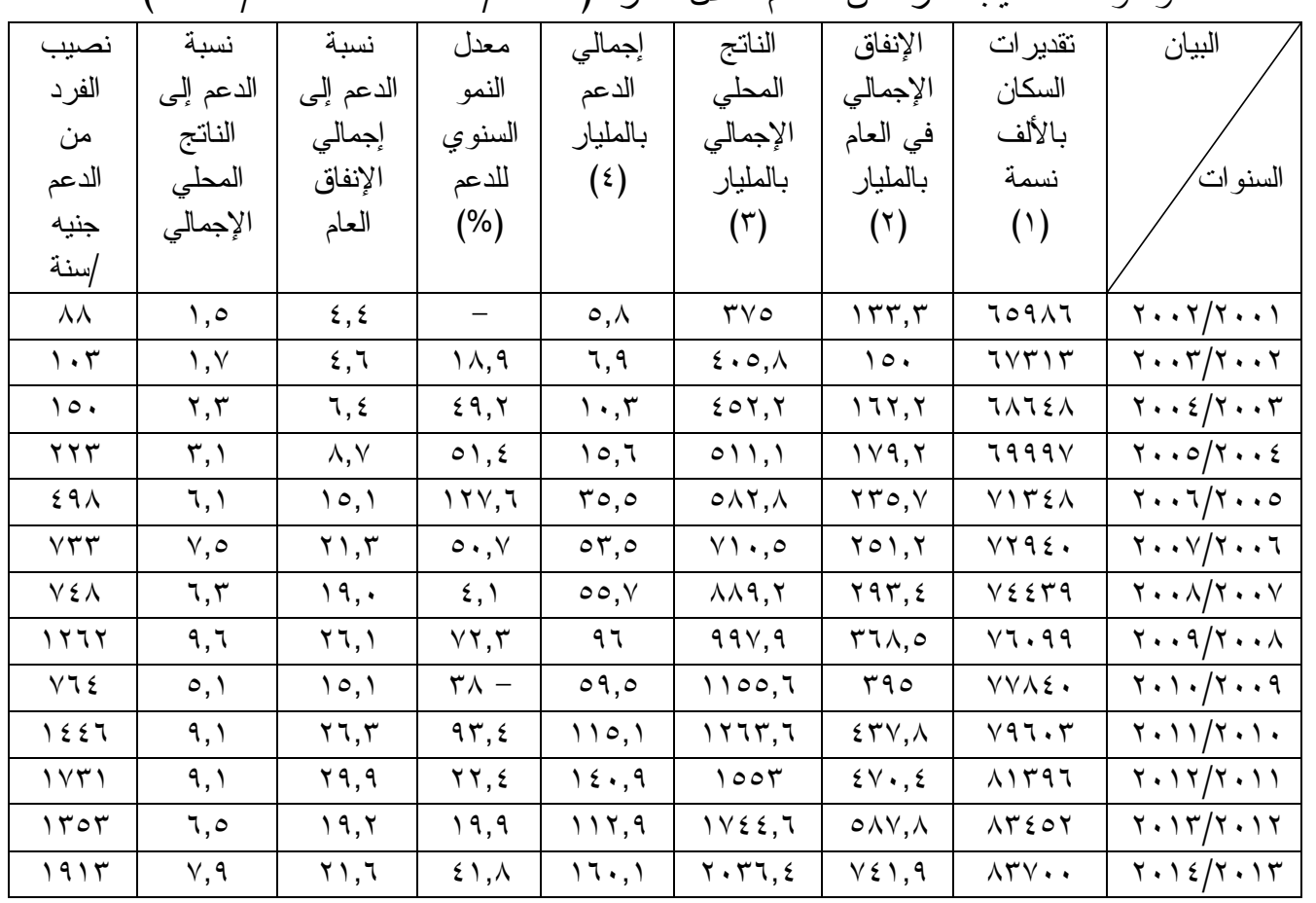

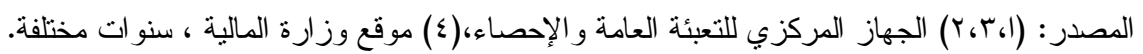




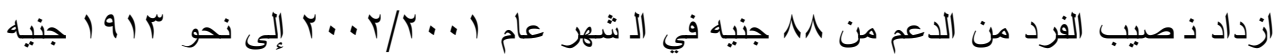

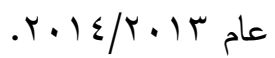

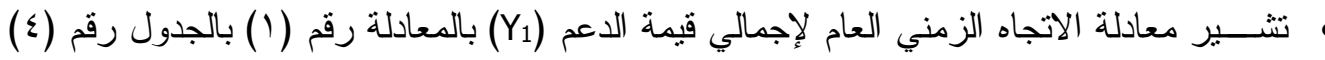

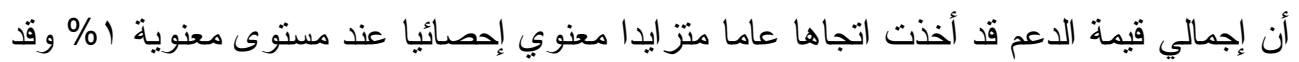

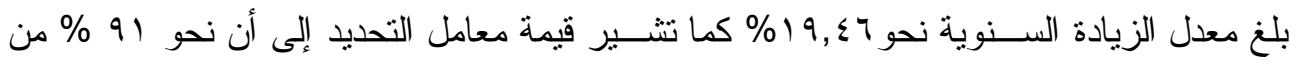

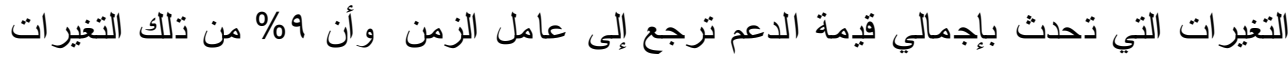

$$
\text { ترجع إلى عو امل أخري غير مقيسه بالنموذج. }
$$

r- تطور الإنفاق على الاعم حسب بنوده المختلفة:

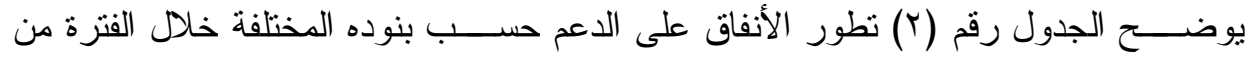

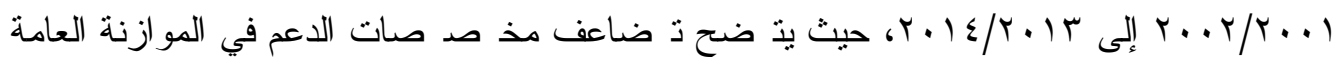

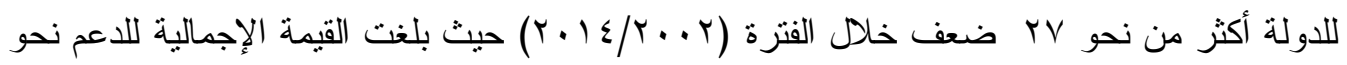

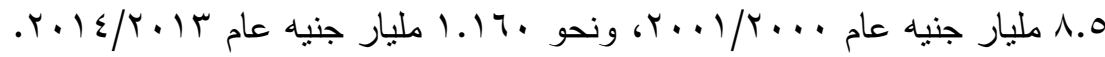
بدر اسة تطور الإنفاق على بنود الدعم المختلفة يلاحظ أن الإنفاق على الاسلع الغذائية المدعمة

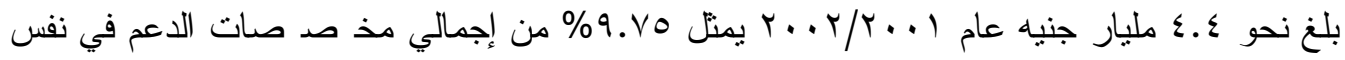

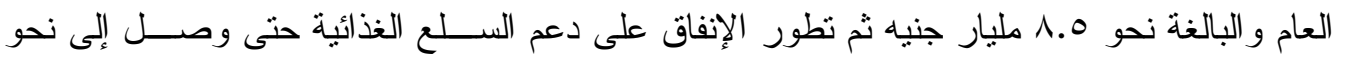

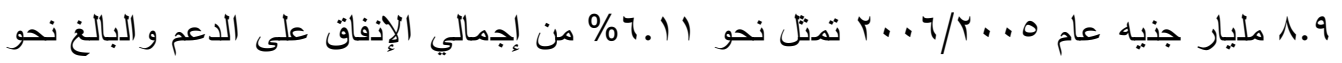

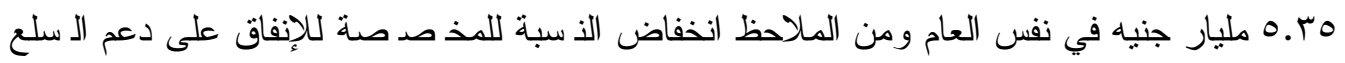
الغذائية من إجمالي الدعم حيث لأول مرة تظهر مخصدصات دمم المو اد البترولية في الموازنة العامة

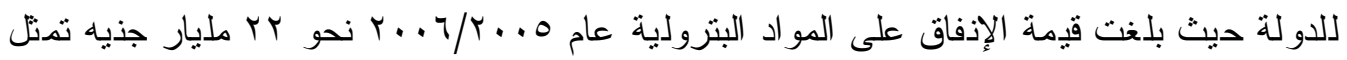
نحو r7\% من إجمالي الدعم و البالغ نحو هr.0 مليار جنيه في نفس العام ثم بعد ذللك ارتفعت القيمة

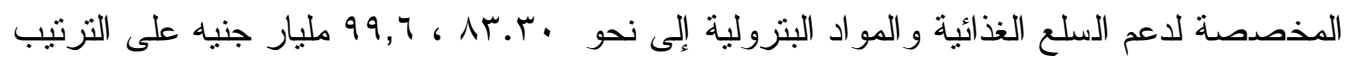

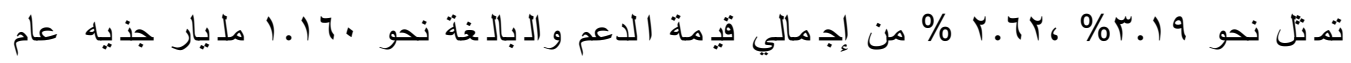
$r \cdot 1 \leq / r \cdot 1 r$ من الملاحظ استحو اذ دعم المواد البترولية على النصيب الأكبر من إجمالي الدعم حيث بلغ دعم المو اد البترولية ثلاث أضعاف المخصص للسلع التموينية (الخبز ، السكر، الزيت، الأرز) وهو النه

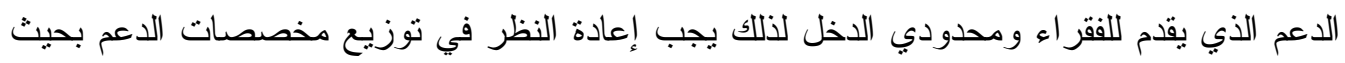
تكون في اتجاه زيادة الدعم الغذائي وذلك بالحد من التوسع في الإنفاق على المواد البترولية والتي تستهدف الأغنياء ومالكي السيار ات و أصحاب المصانع كثثفة الطاقة وخلافه. 
جدول (Y) نطور الإنفاق على الدعم حسب بنوده المختلفة

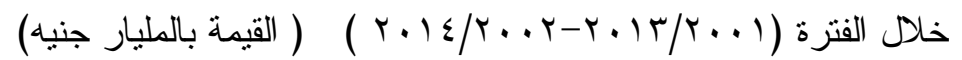

\begin{tabular}{|c|c|c|c|c|c|c|c|c|}
\hline الإعمالي & أخرى & داعم المناطق & الصادر ات & الإسكان & الكهرباء & الدعم المو اد & لدعم السلغ & السنة المالية \\
\hline 0,1 & $\cdot, \lambda$ & - & $\cdot, Y$ & $\cdot, \xi$ & - & - & $\{, \xi$ & $r \ldots r / r \ldots l$ \\
\hline 7,9 & $\cdot, \Lambda$ & - & $\cdot, r$ & $\cdot, V$ & - & - & $0, Y$ & $r \ldots r / r \ldots r$ \\
\hline $1 \cdot, r$ & $\cdot, V$ & - & $\cdot, 7$ & $\cdot, \wedge$ & - & - & $\Lambda, Y$ & $r \ldots \xi / r_{\ldots} . r$ \\
\hline 10,7 & $r, 0$ & - & $\cdot, 0$ & - & - & - & 11,1 & Y...o/r... \\
\hline$r 0,0$ & $Y, V$ & - & 1 & - & - & YY & 9,1 & $Y \ldots T / Y \ldots o$ \\
\hline $0 \%, 0$ & $r, \xi$ & $\cdot, Y$ & 1,0 & 1 & - & $\xi$ & $\lambda, 1$ & $r \ldots v / r_{\ldots}$ \\
\hline $00, Y$ & $\Gamma, \Gamma$ & $1, r$ & $r$ & 1 & $r$ & $r 4,7$ & 9,0 & $r \ldots \lambda / r_{\ldots}$ \\
\hline 97 & $0, \xi$ & $\cdot, \varepsilon$ & $r$ & 1 & $r$ & $T Y, V$ & $Y 1,0$ & $r \ldots q / r_{\ldots} \ldots \Lambda$ \\
\hline 09,0 & $V, 1$ & $\cdot, \xi$ & $r, v$ & 1 & - & $r r, v$ & $1 \%, 7$ & $r .1 . / T . . q 9$ \\
\hline 110,1 & $r$ & $\cdot, \xi$ & $\xi$ & 1 & $7, r$ & $T V, V$ & YY,Y & $r .11 / \% .1$. \\
\hline $1 \leqslant \cdot, 9$ & $0, V$ & $\cdot, \xi$ & $r, 0$ & 1,0 & 0 & 90,0 & $r \cdot, r$ & $\frac{T}{r .1 Y / T .11}$ \\
\hline $11 r, 9$ & 7,9 & $\bar{P}, \xi$ & $r, 1$ & $\overline{r, V}$ & 0 & $v \cdot$ & $Y Y, 7$ & $T .1 T / T .1 Y$ \\
\hline $17 \cdot, 1$ & $I Y, V$ & $\cdot, \xi$ & $r, 1$ & $\cdot, r$ & $I T, Y$ & 99,7 & $\mu \cdot \lambda \mu$ & $1.1 \leqslant / T .1 \%$ \\
\hline $71, \lambda$ & $\varepsilon, Y$ & $\cdot, \Gamma$ & 1,9 & $\cdot, V Y$ & $Y, Y$ & $\varepsilon \cdot, 1$ & $17, \varepsilon$ & المتو سط \\
\hline
\end{tabular}

المصدر : وزارة المالية، البيان المالي عن مشروع الموازنة العامة للاولة، سنوات مختلفة.

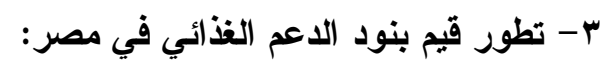

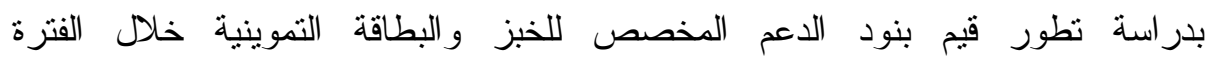

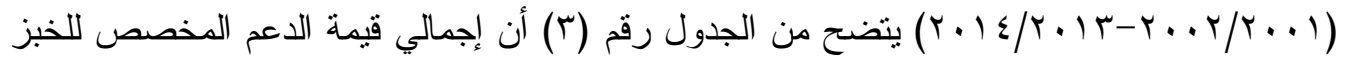

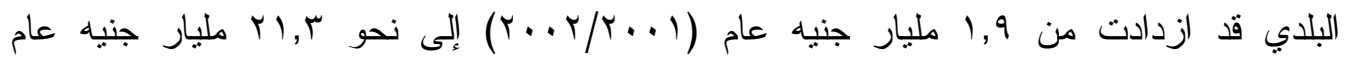

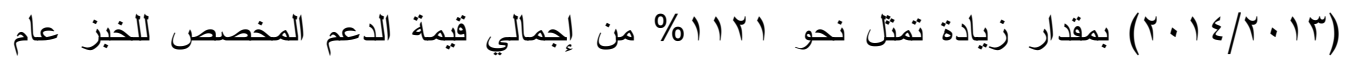

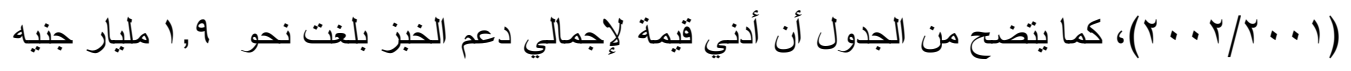

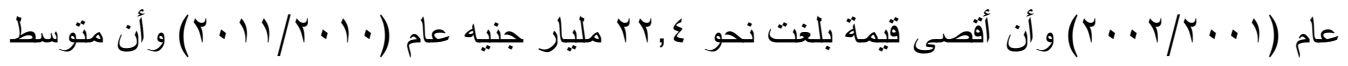

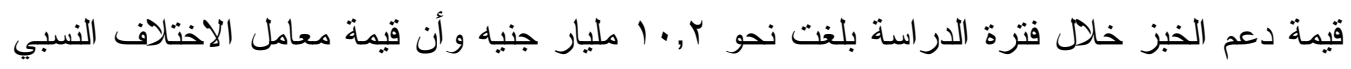
بلغت نحو \%77,07\%

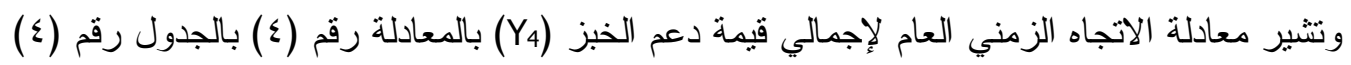

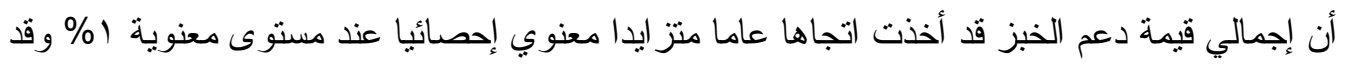

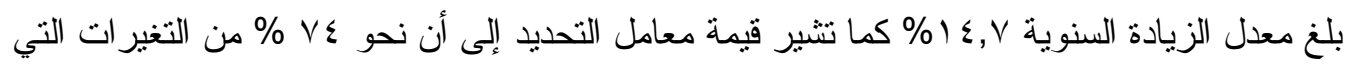

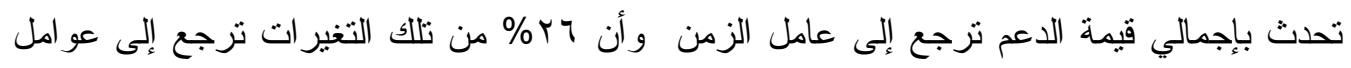
أخري غير مقيسه بالنموذج.

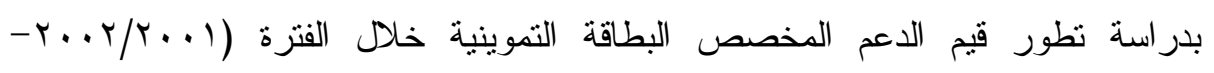

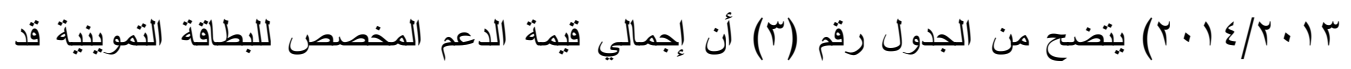

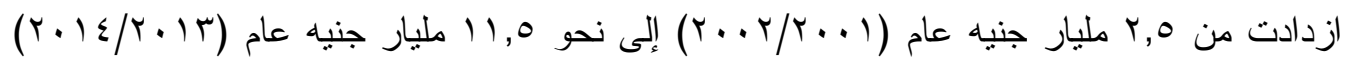

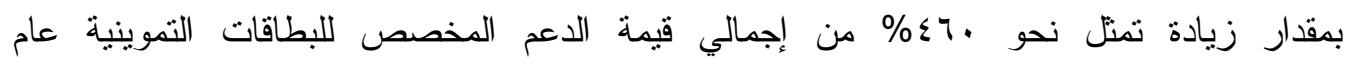

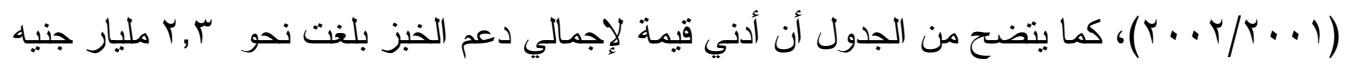

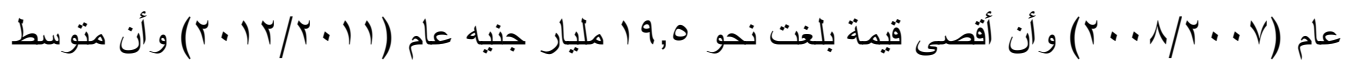


قيمة الدعم للمخصص للبطاقات التموينية خلال فترة الدر اسة بلغ نحو ب, ؟ مليار جنيه و أن قيمة معامل الاختلاف النسبي بلغت نحو 91 \%1,9 وتتثير دعادلة الاتجاه الزمني العام لإجمالي قيمة دعم البطاقات التموينية (Y3) بالمعادلة رقم

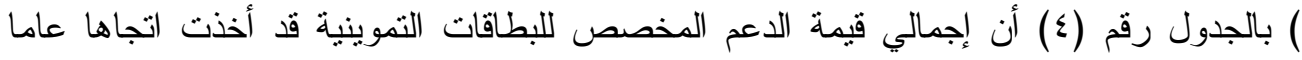
متز ايدا معنوي إحصائيا عند مستوى معنوية (\% وقد بلغ معدل الزيادة السنوية ع,0 \% كما نتير قيمة معامل التحديد إلى أن نحو بor \% من التغير ات التي تحدث بإجمالي قيمة الدعم المخصص للبطاقة

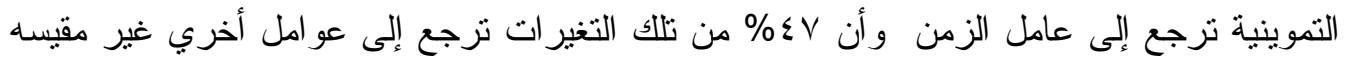
بالنموذج. ع - تطور قيمة دعم السلع الغذائية:

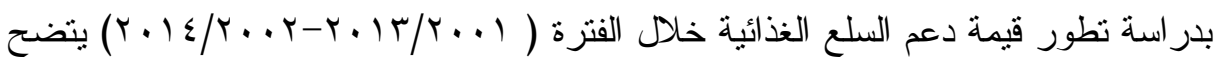

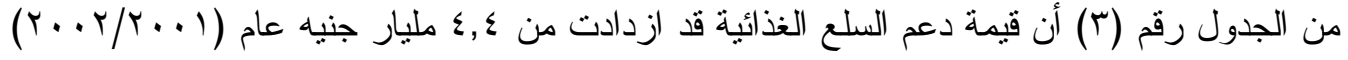

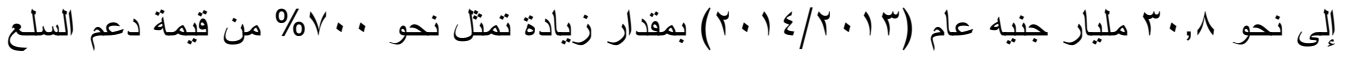

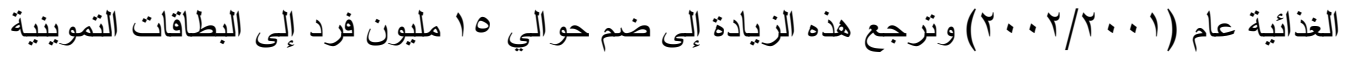
وتحويل الدعم الجزئي إلى دعم كلى ومضاعفة الكميات الإضافية للأفر اد من السلع الغذائية المدعمة

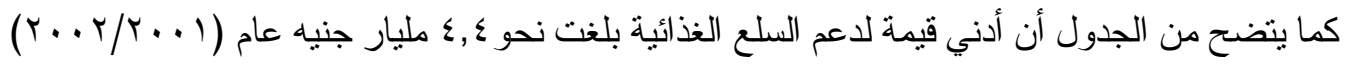

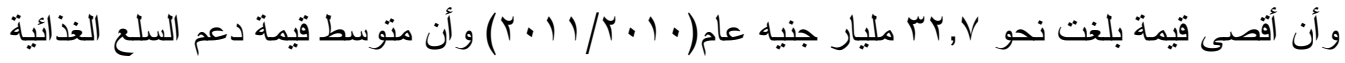
خلال فترة الدراسة بلغت نحو ع,17 مليار جنيه وأن قيمة معامل الاختلاف النسبي بلغت نحو .\% тr,१จ

جدول (r) نطور قيمة دعم السلع الغذائية (الخبز - سلع البطاقة التموينية)

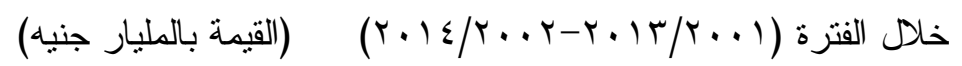

\begin{tabular}{|c|c|c|c|c|}
\hline إجمالي الدعم & 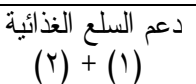 & دعم البطاقة التموينية & دعم رغيف الخبز & السنو ات \\
\hline 0,1 & $\varepsilon g \leqslant$ & $r, 0$ & 1,9 & $r \ldots r / r \ldots l$ \\
\hline 7,9 & $0, r$ & r, Yo & 1,90 & $r \ldots r / r \ldots r$ \\
\hline $1 \cdot, r$ & $\lambda, Y$ & T,乏 & $0, \Lambda$ & $r \ldots \varepsilon / r \ldots r$ \\
\hline 10,7 & 11,7 & 0,1 & 7,0 & r...o/r... \\
\hline$\Gamma_{0,0}$ & $9, \wedge$ & $r, \tau$ & $7, Y$ & $r \ldots T / Y \ldots o$ \\
\hline or,o & $\lambda, 7$ & $r, r$ & $7, r$ & $r \ldots v / r \ldots r$ \\
\hline $00, \mathrm{~V}$ & 9,0 & $\overline{r, r}$ & $\overline{V, Y}$ & $r \ldots \Lambda / r \ldots V$ \\
\hline 97 & YI,0 & $0, \varepsilon$ & 17,1 & $r \ldots q / r \ldots \lambda$ \\
\hline 09,0 & $1 \pi, 7$ & $r, \tau$ & 1. & $r \cdot 1 \cdot / r \ldots q$ \\
\hline 110,1 & $r Y, V$ & $1 \cdot r$ & YY, & $r .11 / r \cdot 1$. \\
\hline $1 \leqslant \cdot, 9$ & $r \cdot, r$ & 19,0 & $1 \cdot, \wedge$ & $r .1 r / r \cdot 11$ \\
\hline $11 r, 9$ & YY, & $\overline{1 \cdot, \varepsilon}$ & $17, r$ & $r \cdot I T / r \cdot I r$ \\
\hline $17 \cdot, 1$ & $r \cdot, \Lambda$ & 11,0 & $r, r$ & $r \cdot 1 \leqslant / r .1 T$ \\
\hline $77, \wedge$ & $17, \xi$ & $7, \Gamma$ & $1 \cdot, r$ & المتوسط \\
\hline or, r & $1 \cdot, 0$ & $0, Y$ & $7, \wedge$ & الانحر اف المعياري \\
\hline $10 \leqslant, \Gamma$ & $r \wedge, r$ & $I V, r$ & $r \cdot, 0$ & المدى \\
\hline $0, \Lambda$ & $\xi, \varepsilon$ & $r, r$ & 1,9 & أدنى قيمة \\
\hline $17 \cdot, 1$ & TY,V & 19,0 & YY, $\varepsilon$ & أعلى قيمة \\
\hline$v 9,79$ & $7 r, 9 V$ & 11,97 & 77,07 & معامل الاختلاف النسبي \\
\hline
\end{tabular}




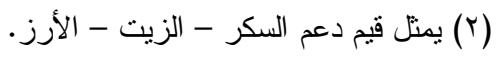

وتتير معادلة الاتجاه الزمني العام لقيمة دعم السلع الغذائية (Y2) بالمعادلة رقم (Y) بالجدول

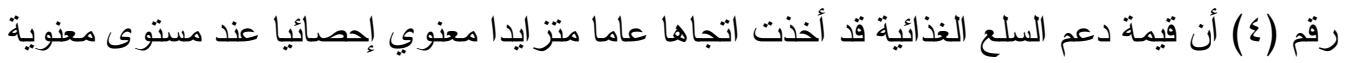

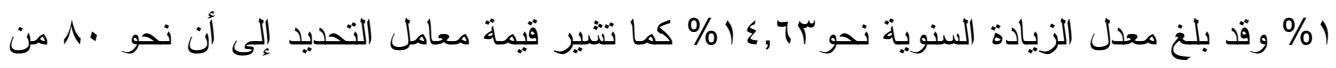

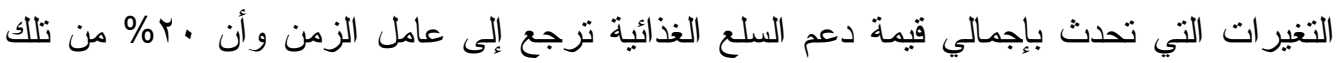
التغير ات نزجع إلى عو امل أخري غير مقيسه بالنموذج. جدول (乏) تقدير معادلات الاتجاه الزمني العام لتطور الانفاق على الدعم

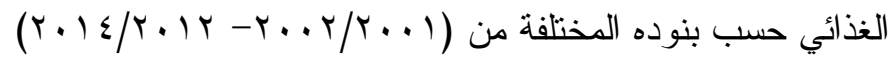

\begin{tabular}{|c|c|c|c|c|c|c|}
\hline 亨 & $\mathrm{F}$ & $\mathrm{R}^{2}$ & السنوي (\%) & النموذج & المتغير & $\begin{array}{l}92 \\
\overline{3} \\
\frac{3}{3} \\
\vdots\end{array}$ \\
\hline 0.01 & 106.7 & 0.91 & 19.46 & $\begin{array}{l}Y_{1}=-24.29+13 t \\
\quad(-2.34)^{*} \\
(10.33)^{* *}\end{array}$ & إجمالي الدعم & 1 \\
\hline 0.01 & 43. 9 & 0.80 & 14.63 & $\begin{array}{l}Y_{2}=-0.46+2.40 t \\
\quad(-0.16) \\
(6.62)^{* *}\end{array}$ & دعم السلع الغذائية & r \\
\hline 0.01 & 12.6 & 0.53 & 15.4 & $\begin{aligned} Y_{3}= & -0.48+0.97 t \\
& (-0.22) \quad(3.54)^{* *}\end{aligned}$ & دعم البطاقة التموينية & $r$ \\
\hline 0.01 & 31.1 & 0.74 & 14.7 & $\begin{aligned} Y 4= & -0.29+1.5 \mathrm{t} \\
& (-0.14)(5.58)^{* *}\end{aligned}$ & قيمة دعم الخبز & $\varepsilon$ \\
\hline
\end{tabular}

المصدر : حسبت من بيانات الجدول رقم (r) أهم القضايا المتعلقة بتطبيق منظومة الدعم الغذائي 1 - كفاية الكميات التي تصرف على البطاقة لتموينية:

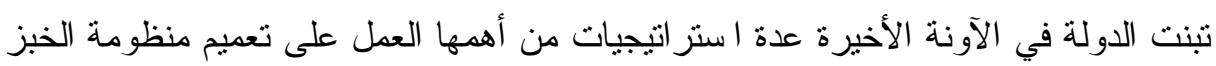

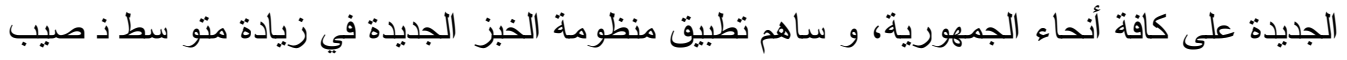

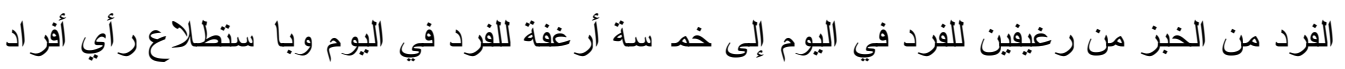

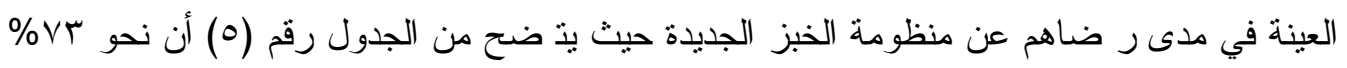

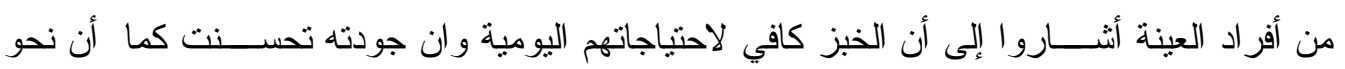

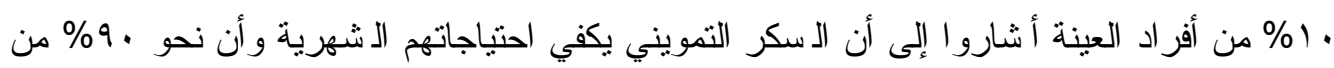

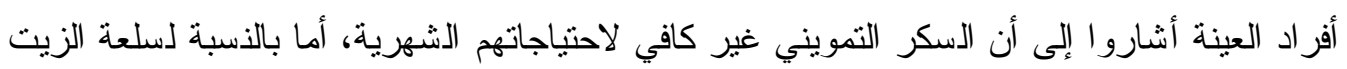
التمويني فأشار 0\% فقط من أفر اد العينة أن الزيت يكفي احتباجاتهم الشهرية في حين أن نحو

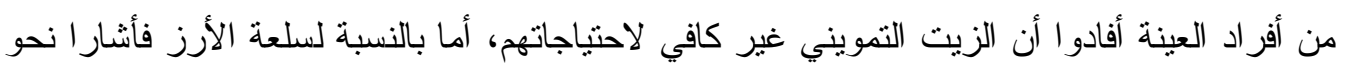

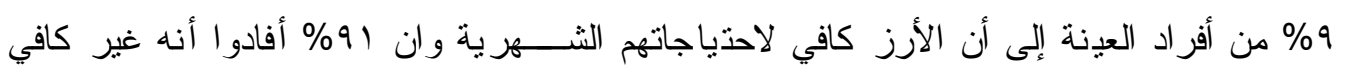


لاحتياجاتهم الـ شهرية ويتبين مما سبق ان الكميات من الـ سلع التموينية ( الـ سكر ، الزيت ، الارز) لا تكفي الاستهلاك الثهري للفرد.

$$
\text { r - بعوبات في الصرف: }
$$

باسنطلاع ر أي أفر اد العينة في ددى وجود صعوبات في صرف المقررات التموينية في ظل

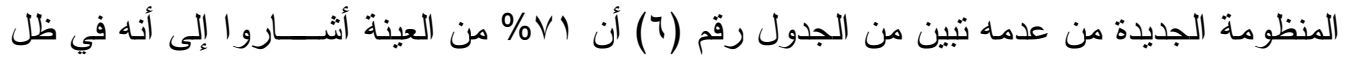
تطبيق المنظومة الجديدة لا تو اجهرم صعوبات في صرف المقررات التموينية في حين أن نحو وبنه

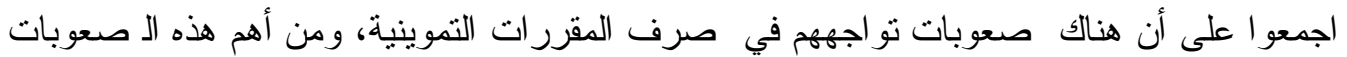

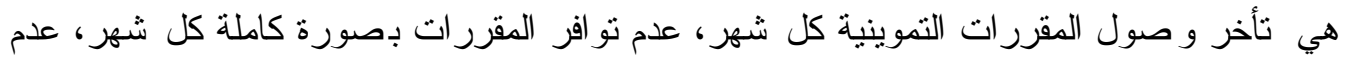
كفاية السلع و عدم تتوعها، صرف المقررات على مرتين في الشهر، الزحام الشديد و وانخفاض جودة لدرة بعض السلع. جدول (0) رأي أفر اد العينة في مدى كفاية الكميات التي تصرف

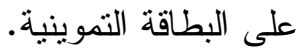

\begin{tabular}{|c|c|c|c|c|c|c|c|c|c|c|c|c|}
\hline \multicolumn{4}{|c|}{ المجموع } & \multicolumn{4}{|c|}{ الحضر } & \multicolumn{4}{|c|}{ الريف } & \multirow{3}{*}{ السلعة } \\
\hline \multicolumn{2}{|c|}{ غير كافي } & \multicolumn{2}{|c|}{ كافي } & \multicolumn{2}{|c|}{ غير كافي } & \multicolumn{2}{|c|}{ كافي } & \multicolumn{2}{|c|}{ غير كافي } & \multicolumn{2}{|c|}{ كافي } & \\
\hline$\%$ & العدد & $\%$ & العدد & $\%$ & العدد & $\%$ & العدد & $\%$ & العدد & $\%$ & العدد & \\
\hline TV & $\varepsilon$. & $V T$ & 11. & $\Lambda$ & $\varepsilon$ & 94 & $\sum 7$ & דו & ru & T & $T \varepsilon$ & الخبز \\
\hline 9. & 1ro & 1. & 10 & $9 \leqslant$ & $\leqslant V$ & 7 & $r$ & $\Lambda \Lambda$ & $\Lambda \wedge$ & Ir & Ir & السكر \\
\hline 90 & $1 \leqslant r$ & 0 & $\wedge$ & 9. & $\leqslant 0$ & 1. & 0 & 9V & १V & $r$ & $r$ & الزيت \\
\hline 9) & 4Tו & 9 & $1 \varepsilon$ & $9 \leqslant$ & $\leqslant V$ & 7 & $r$ & 19 & 19 & 11 & 11 & الأرز \\
\hline
\end{tabular}

المصدر : جمعت وحسبت من بيانات استمارة الاستبيان. جدول (T) مدى وجود صعوبات نو اجه افر اد عينة الدر اسة في الحصول على الكمية المقررة شهريا من السلع الغذائية المدعمة.

\begin{tabular}{|c|c|c|c|c|c|c|}
\hline \multirow{2}{*}{$\%$} & \multirow{2}{*}{ المجموع } & \multicolumn{2}{|c|}{ الحضر } & \multicolumn{2}{|c|}{ الريف } & \multirow{2}{*}{ 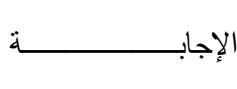 } \\
\hline & & $\%$ & العدد & $\%$ & العدد & \\
\hline rq & $\varepsilon \varepsilon$ & rY & 11 & r & r & نعم يوجد صعوبات \\
\hline vi & 1.7 & VA & rq & TV & TV & لا يوجد صعوبات \\
\hline $1 \ldots$ & 10. & $1 \ldots$ & 0. & $1 \ldots$ & $1 \ldots$ & المجموع \\
\hline
\end{tabular}




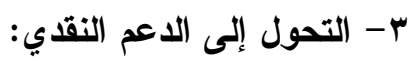

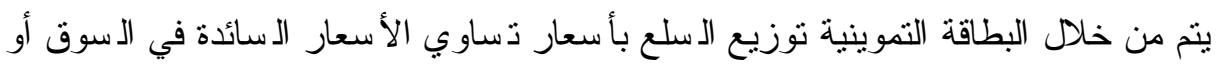

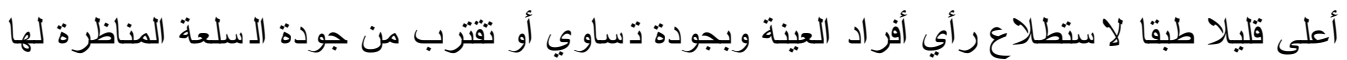

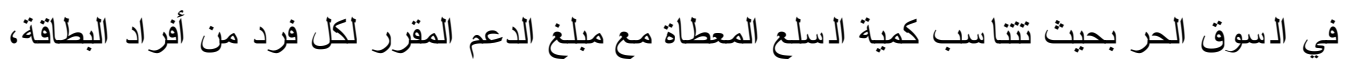
ويعيب على هذا النظام أنه يؤدي إلي حدوث بعض المشاكل منها عدم تو افر بعض السلع الضرورية وتأخر البعض الأخر منل الزيت والأرز وفي بعض الأحيان تلاعب البقال التمويني في تمرير البطاقة

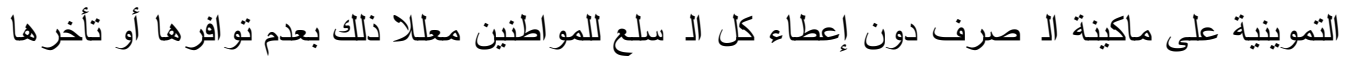
بالإضـــافة لفرض رســوم على الموطنين غير فعليه ويحدث كل ذلك في ظلل عدم وجود رقابة فعالة

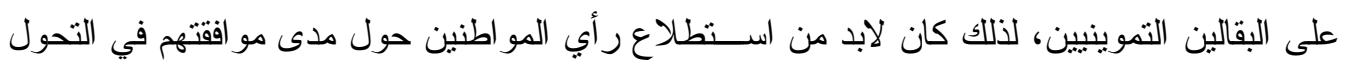

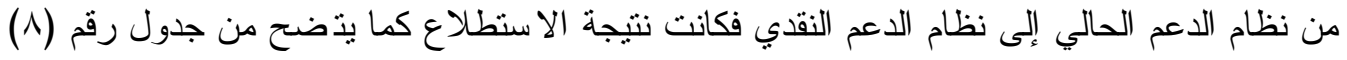

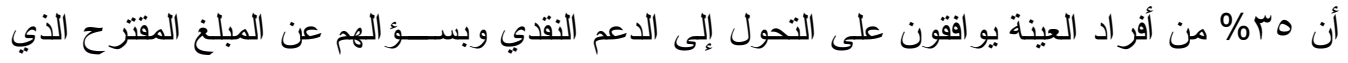

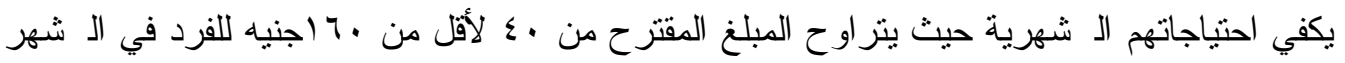

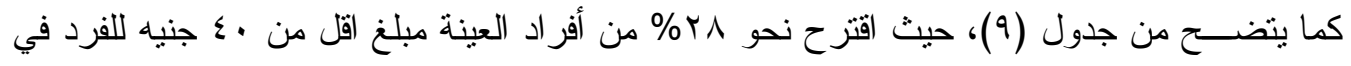

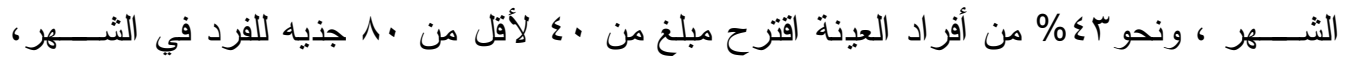

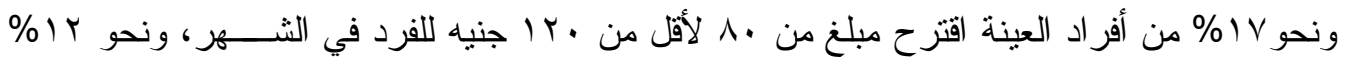

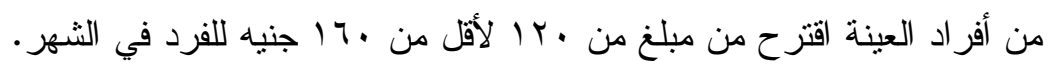
جدول (^) مدى مو افقة افر اد العينة على استبدال الدعم العيني بدعم نقدي.

\begin{tabular}{|c|c|c|c|c|c|c|}
\hline \multirow[t]{2}{*}{$\%$} & \multirow{2}{*}{ المجموع } & \multicolumn{2}{|c|}{ الحضر } & \multicolumn{2}{|c|}{ الريف } & \multirow{2}{*}{ 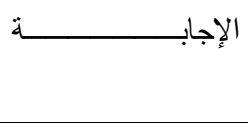 } \\
\hline & & $\%$ & العدد & $\%$ & العدد & \\
\hline ro & or & 17 & ir & $\varepsilon 1$ & $\leqslant 1$ & مو افق \\
\hline 70 & $9 V$ & $\wedge \varepsilon$ & ऍی & 09 & 09 & غير مو افق \\
\hline $1 \ldots$ & 10. & $1 \ldots$ & 0. & $1 \ldots$ & $1 \ldots$ & المجموع \\
\hline
\end{tabular}

المصدر : جمعت وحسبت من بيانات استمارة الاستبيان. جدول (9) قيمة المبلغ المقترح للفرد شهريا في حالة استبدال الدعم العيني بدعم نقدي.

\begin{tabular}{|c|c|c|c|c|c|c|}
\hline \multirow{2}{*}{$\%$} & \multirow{2}{*}{$\begin{array}{l}\bar{\alpha} \\
\bar{\alpha}\end{array}$} & \multicolumn{2}{|r|}{ 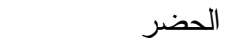 } & \multicolumn{2}{|r|}{ 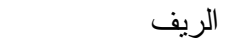 } & \multirow{2}{*}{ 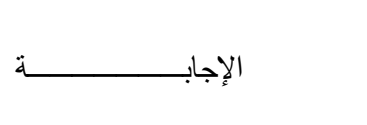 } \\
\hline & & $\%$ & العدد & $\%$ & العدد & \\
\hline rᄉ & 10 & TV & $\wedge$ & iv & v & اقل من · عجنيه شهريا \\
\hline$\varepsilon r$ & rr & r & $\varepsilon$ & $\leqslant 7$ & 19 & من • ـ إلى أقل من •^ جنيه \\
\hline iV & 9 & - & - & rr & 9 & من •^ إلى اقل من • Y اجنيه \\
\hline ir & 7 & - & - & 10 & 7 & من • Y ا إلى اقل من • 1 ا جنيه \\
\hline $1 \ldots$ & or & $1 \ldots$ & ir & $1 \ldots$ & 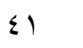 & 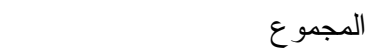 \\
\hline
\end{tabular}

المصدر : جمعت وحسبت من بيانات استمارة الاستنيان. 


\section{؛ - مستوى الرضا عن منظومة الدعم الغذائي}

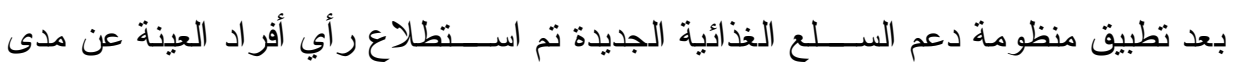

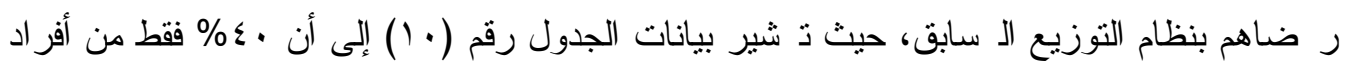

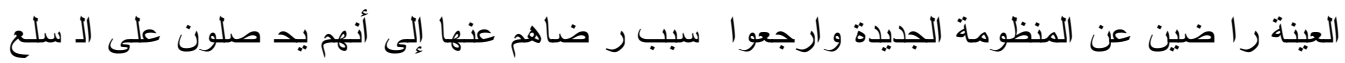

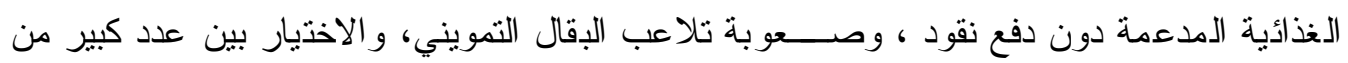

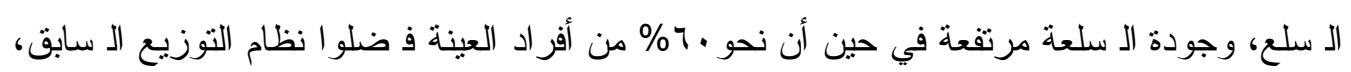

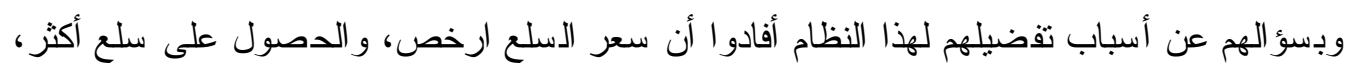
ويساعدنا في الحصد ــول السلع الضرورية، ويساهم في تخفيض أسعار السلع الحرة المماتلة، وكميات

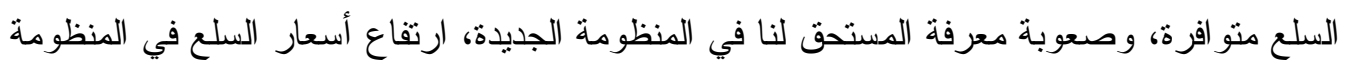

جدول (• ()) رأي افر اد العينة في أفضلية نظام التوزيع.

\begin{tabular}{|c|c|c|c|c|c|c|}
\hline \multirow{2}{*}{$\%$} & \multirow{2}{*}{$\begin{array}{l}\overline{3} \\
\text { a }\end{array}$} & \multicolumn{2}{|c|}{ الحضر } & \multicolumn{2}{|c|}{ الريف } & \multirow{2}{*}{ النظام } \\
\hline & & $\%$ & العدد & $\%$ & العدد & \\
\hline$\varepsilon \cdot$ & 7. & $\varepsilon r$ & r) & rq & rq & لمنظومة الجديدة \\
\hline 7. & 9. & $0 \wedge$ & rq & 71 & 71 & النظام السابق \\
\hline $1 \ldots$ & 10. & $1 \ldots$ & 0 . & $1 \cdots$ & $1 \ldots$ & المجموع \\
\hline
\end{tabular}

المصدر : جمعت وحسبت من بيانات استمارة الاستنبان.

ه- أهم المشاكل التي تواجهه تطبيق منظومة الاعم الغذائي:

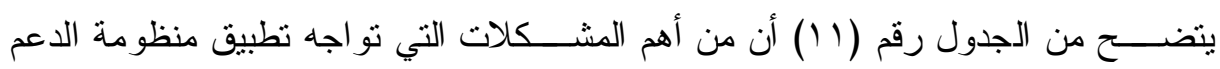

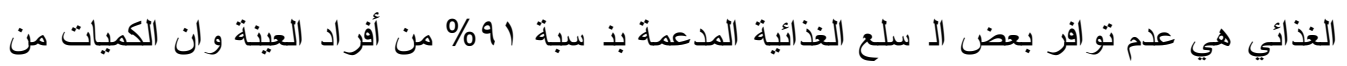

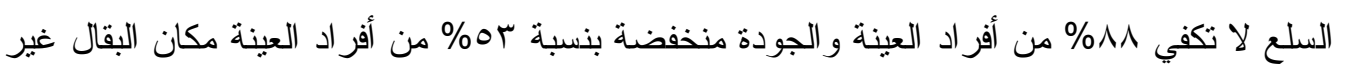

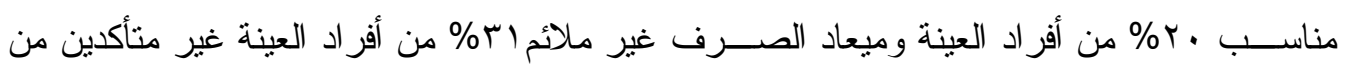
الحصول الدعم المقرر بالكامل \%00\% من أفر اد العينة.

\begin{tabular}{|c|c|c|c|c|c|c|}
\hline \multirow{2}{*}{$\%$} & \multirow{2}{*}{ الغد } & \multicolumn{2}{|c|}{ الحضر } & الريف & نشاكل الر & \multirow{2}{*}{ 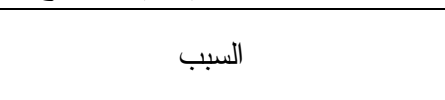 } \\
\hline & & $\%$ & العدد & $\%$ & العدد & \\
\hline 9) & 1147 & A. & $\varepsilon$. & 97 & 97 & عدم تو افر بعض السلع \\
\hline 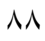 & ITr & $\Lambda \varepsilon$ & $\varepsilon r$ & 9. & 9. & الكمبات من السلع لا تكفي \\
\hline or & $\wedge$. & 01 & rq & 01 & 01 & الجودة منخفضة \\
\hline$r$. & $r$. & $r$. & 10 & 10 & 10 & مكان البقال غير مناسب \\
\hline$\mu_{1}$ & $\varepsilon V$ & ז & 11 & rq & rq & ميعاد الصرف غير ملائم \\
\hline 00 & Ar & $r_{\Lambda}$ & 19 & זיד & זי & غالكامل منأكدين من الحصول الدعم المقرر \\
\hline
\end{tabular}

المصدر : جمعت وحسبت من بيانات استمارة الاستيان. 


\section{مساهمة السلع الغذائية المدعمة في تغطية احتياجات أسر عينة الدراسة 1- مساهمة الخبز المدعم في الاستهلاك الاجمالي للأسرة:}

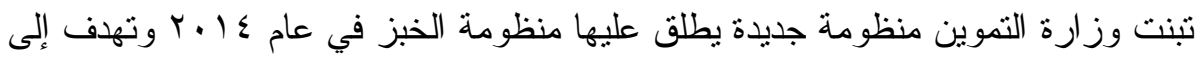

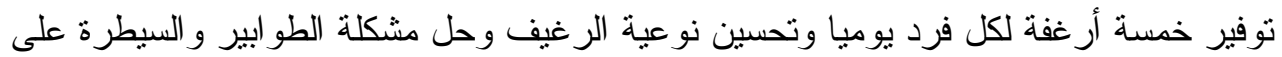
ظاهرة تسرب الدقيق المدعم، وبالتالي توصيل الدعم إلى مستحقيه بدلا من إهدار جزء كبير لا يستهان به من هذا الدعم لمحدودي الدخل وفي هذه الدر اسة سوف يتم التعرف على مدى مساهمة نسبة الخبز المدعم في الاستهلاك الإجمالي للأسرة.

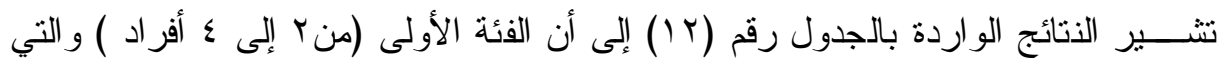

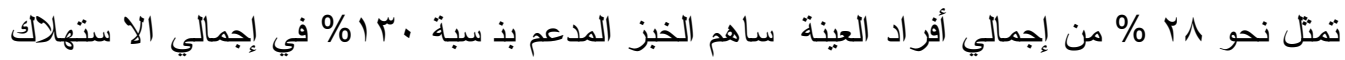

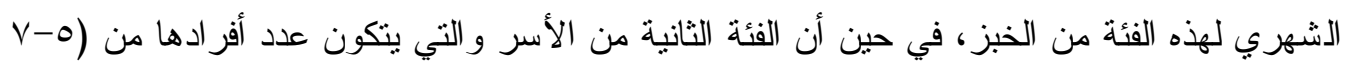

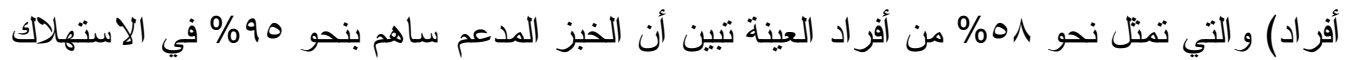

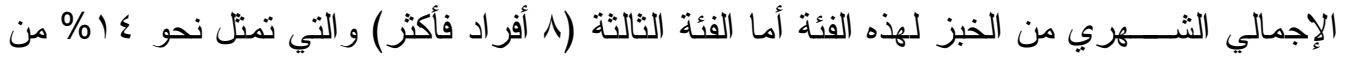
أفر اد العينة بعد تطبيق المنظومة الجديدة ساهم الخبز المدعم بذ سبة ـ9\% في إجمالي الا ستهلاك الثهري لهذه الفئة.

\section{r- مساهمة السكر العدعم في الاستهلاك الاجمالي للأسرة:}

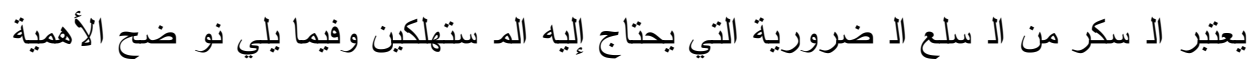

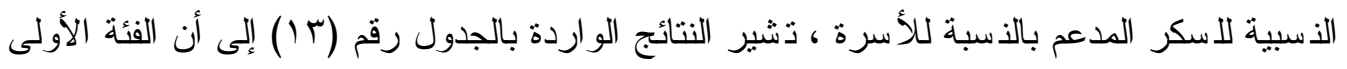

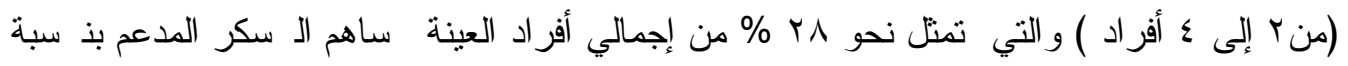

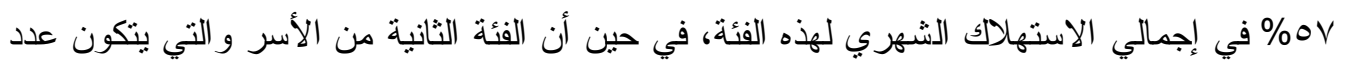

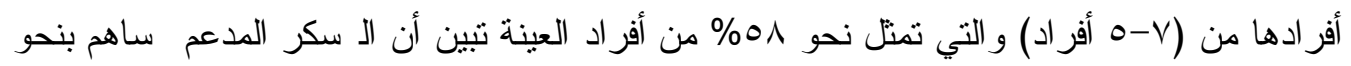

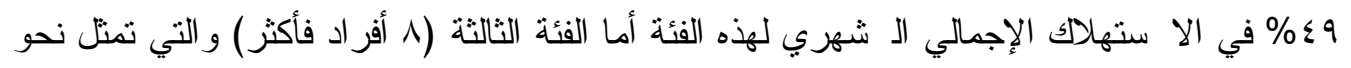

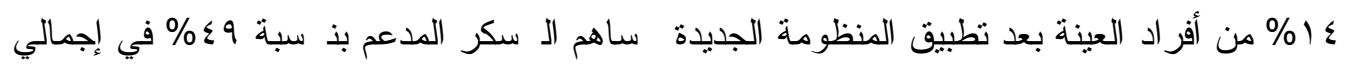
الاستهلاك الشهري لهذه الفئة.

جدول (r) نسبة مساهمة الخبز البلدي المدعم في الاستهلاك الإجمالي للأسرة من الخبز .

\begin{tabular}{|c|c|c|c|c|c|}
\hline \multirow{2}{*}{ \% للاستفادة } & \multirow{2}{*}{$\%$} & \multirow{2}{*}{ العلد } & الحضر & الريف & \multirow{2}{*}{ أفر اد الأسرة } \\
\hline & & & \% للاستفادة & \% للاستفادة & \\
\hline 14. & rA & $\varepsilon r$ & 100 & 9. & من ك إلى ع أفر اد \\
\hline 90 & 01 & NV & $11 \mathrm{~V}$ & N4 & من ه إلى أفر اد V \\
\hline 9. & $1 \varepsilon$ & r) & - & 9. & ^ أفر اد فأكثر \\
\hline- & $1 \ldots$ & 10. & - & - & المجموع \\
\hline
\end{tabular}

المصدر: جمعت وحسبت من بيانات استمارة الاستيان. 
جدول (ז ا) نسبة مساهمة السكر المدعم في الاستهلاك الإجمالي للأسرة.

\begin{tabular}{|c|c|c|c|c|c|}
\hline \multirow{2}{*}{ \% للاستفادة } & \multirow{2}{*}{$\%$} & \multirow{2}{*}{ العلد } & الحضر & الريف & \multirow{2}{*}{ أفر اد الأسرة } \\
\hline & & & \% للاستفادة & \% للاستفادة & \\
\hline or & rᄉ & $\varepsilon r$ & 7. & 0 . & من r إلى ع أفر اد \\
\hline$\leq 9$ & 01 & AV & 7. & \{0 & من ه إلى أفر اد V \\
\hline$\leqslant 9$ & $1 \varepsilon$ & ru & - & $\leq 9$ & ^ أفر اد فأكثر \\
\hline - & $1 \ldots$ & 10. & - & - & الدجموع \\
\hline
\end{tabular}

المصدر: جمعت وحسبت من بيانات استمارة الاستيبان.

r- مساهمة الزيت المدعم في الاستهلاك الاجمالي للأسرة:

يعتبر الزيت من الـ سلع الـ ضرورية التي يحتاج إليه الد ستهلكين و هناك فجوة بين الإنتاج

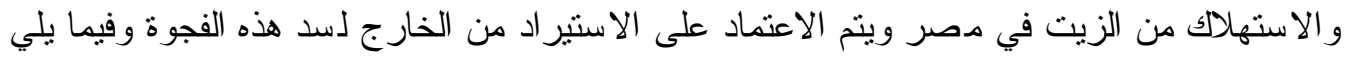

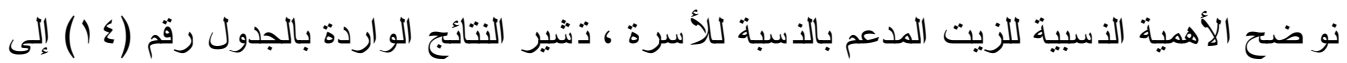

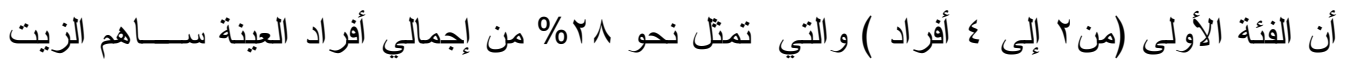

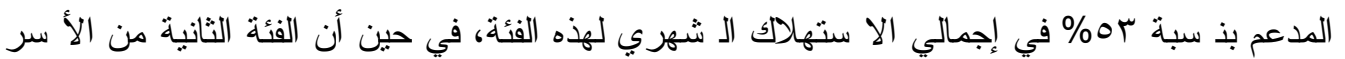

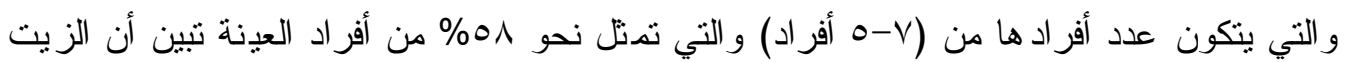
المدعم ساهم بنحو V乏\% في الاستهلالك الإجمالي الشهري لهذه الفئة أما الفئة الثالثة (1 أفر اد فأكثر )

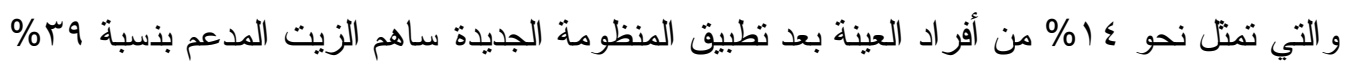
في إجمالي الاستهلاك الثهري لهذه الفئة. جدول (ع () نسبة مساهمة الزيت المدعم في الاستهلاك الإجمالي للأسرة.

\begin{tabular}{|c|c|c|c|c|c|}
\hline \multirow[b]{2}{*}{ \% للاستفادة } & \multirow[b]{2}{*}{$\%$} & \multirow[b]{2}{*}{ العدد } & الحضر & الريف & \multirow[b]{2}{*}{ فر اد الأسرة } \\
\hline & & & \% للاستفادة & \% للاستفادة & \\
\hline or & rᄉ & $\varepsilon r$ & 7. & $\varepsilon r$ & من r إلى ؟ أفر اد \\
\hline$\varepsilon V$ & 01 & NV & r & «1 & V من O إلى أفر اد V \\
\hline rq & $1 \leqslant$ & r) & - & rq & ^ أفر اد فأكثر \\
\hline- & $1 \ldots$ & 10. & - & - & المجموع \\
\hline
\end{tabular}

المصدر : جمعت وحسبت من بيانات استمارة الاستبيان.

ع - مساهمة الأرز المدعم في الاستهلاك الاجمالي للأسرة:

يعتبر الأرز المحصول الوحيد في مجموعة الحبوب الذي يزيد إنتاجه عن استهلاكه في مصر ويتم ت صدير الفائض منه و الذي يقدر بنحو ؟ ٪ وفيما يلي نو ضح الأهمية الذ سبية للا ستفادة بالأرز

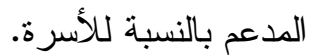




\begin{tabular}{|c|c|c|c|c|c|}
\hline \multirow{2}{*}{$\begin{array}{c}\text { للاستفادة } \\
\text { ل }\end{array}$} & \multirow{2}{*}{$\%$} & \multirow{2}{*}{ 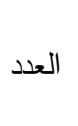 } & الحضر & الريف & \multirow{2}{*}{ أفراد الأسرة } \\
\hline & & & \% للاستفادة & \% للاستفادة & \\
\hline rv & r^ & $\varepsilon r$ & rq & $r \varepsilon$ & من r إلى ع أفر اد \\
\hline r & $0 \wedge$ & $\wedge \vee$ & זr & $r$. & من ه إلى أفر اد V \\
\hline ro & $1 \varepsilon$ & r & - & ro & ^ أفر اد فأكثر \\
\hline- & $1 \ldots$ & 10. & - & - & المجموع \\
\hline
\end{tabular}

المصدر : جمعت وحسبت من بيانات استمارة الاستبيان. تشير النتائج الواردة بالجدول رقم (10) إلى أن الفئة الأولى (من ب إلى ع أفراد ) و التي التي

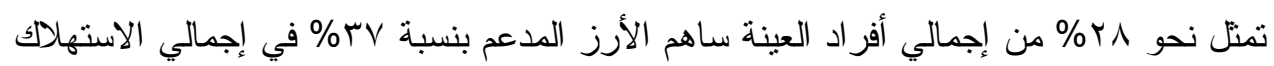

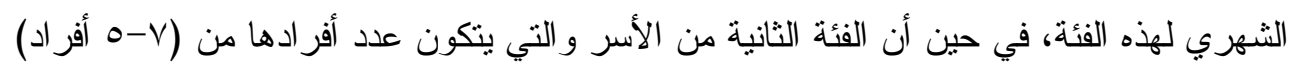

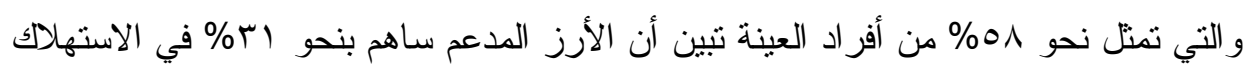

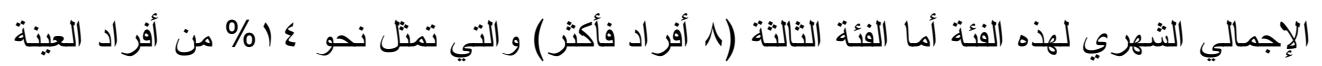

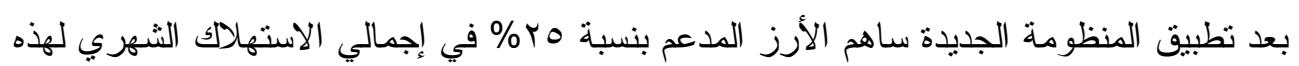

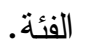

\section{المستلخص}

أوضحت نتائج الدراسة أن نحو 90\% من أفر اد العينة لا يكفيهم مبلغ الدعم المقرر لكل فرد مسجل بالبطاقة التموينية وبالتالي عدم كفاية السلع الغذائية التي تصرف على البطاقة التموينية لادية وعدم

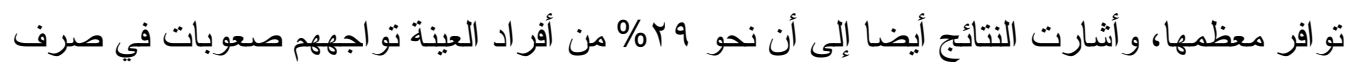

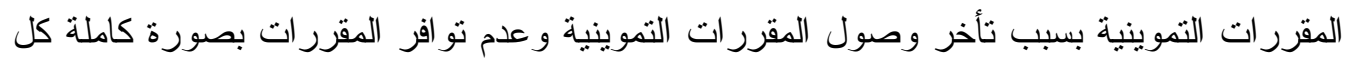

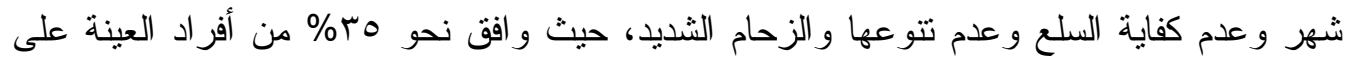

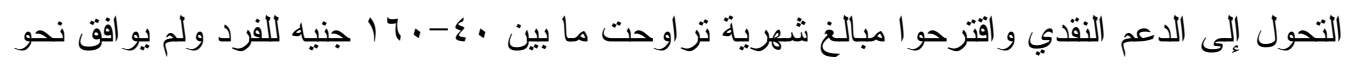

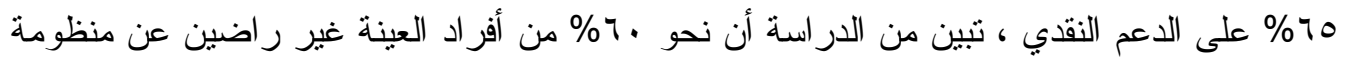

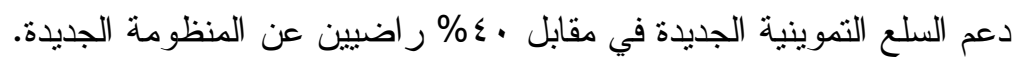
بتقدير نسبة مساهمة السلع الغذائية المدعمة في تغطية احتياجات الاسر المستقيدة بالدعم الغذائي (الخبز

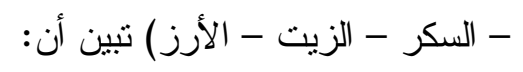
الخبز المدعم ساهم بنحو ه. 1\% في الاستهلاك الإجمالي من الخبز لكل أفراد الأسرة بعينة الدراسة

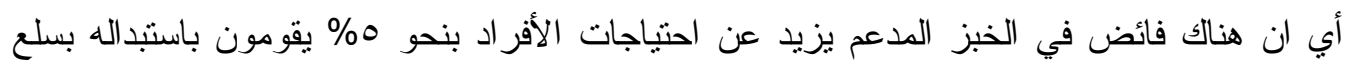

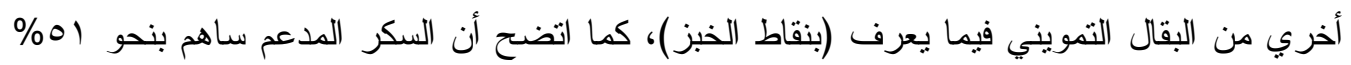

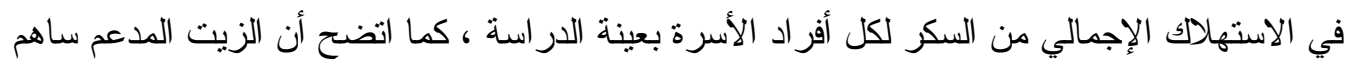

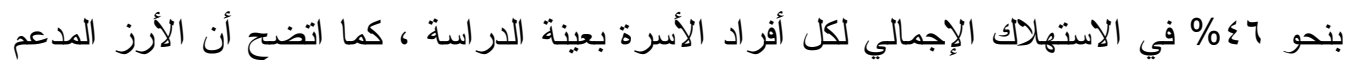
ساهم بنحو اب\% في الاستهلاك الإجمالي من السكر لكل أفراد الأسرة بعينة الدراسة. 


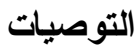

هنالك ضرورة قصوى للإبقاء على الدعم باعنباره احد الآليات التي تستخدمها الدولة في تطبيق قدر اكبر من العدالة في توزيع الدخل وفي تمكين نسبة كبيرة من المجتمع في موجهة تكاليف المعيشة

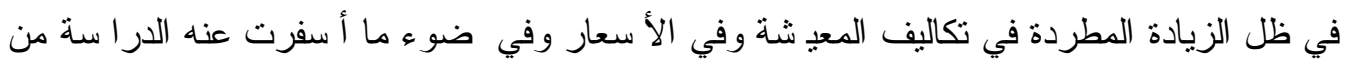
نتائج فأنه يمكن التوصية بما يلي:

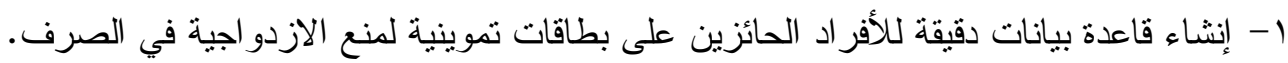

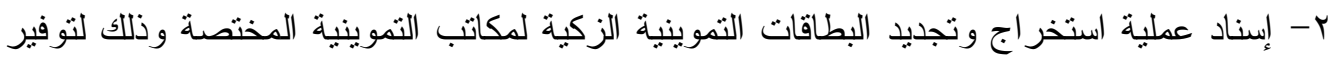
الوقت وفي نفس الوقت تجنب حرمان أصحاب البطاقات التموينية التالفة أو المفقودة من الدعم

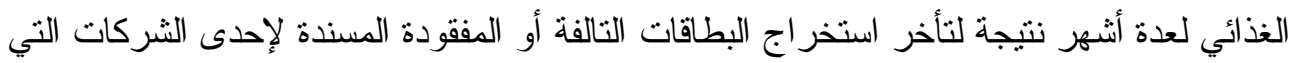

$$
\text { تتبع وزارة الطير ان المدني. تصني. }
$$

r- وضع القو انين التي تحكم وتجرم التلاعب في المنظومة لضمان أداء عملها بكفاءة. ع- وضع آليه مناسبة لتخفيض قيمة دعم المو اد البنرولية والذي يقتطع جزء كبير من إجمالي الدعم ويؤثر على قيمة الدعم الموجه للمو اد الغذائية. 0- العمل على الاهتمام بالريف أكثر من الحضر نتيجة لارتفاع معدلات الفقر في الريف عن الحضر .

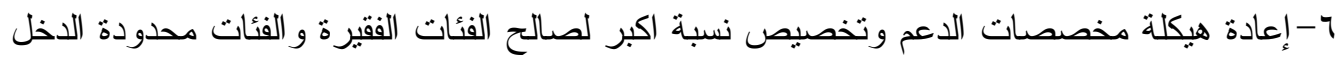
مع استبعاد غير المستحقين حتى يصل الدعم إلى مستحقيه الفعليين. V- ضرورة أستهدف الأفر اد بكميات محددة من السلع الضرورية من خلال بطاقة التموين مع مر اعاة جودة هذه السلع وتوفيره كل شهر بانتظام.

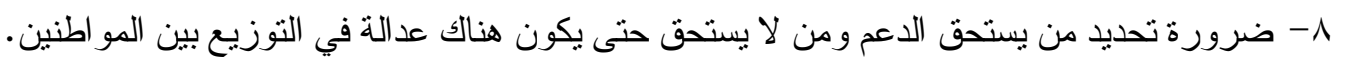

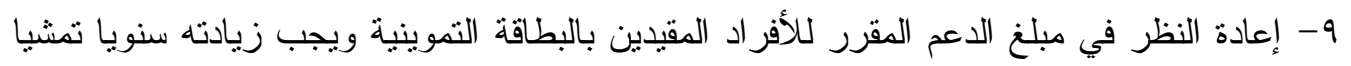

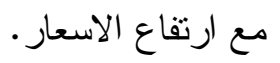

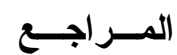

1 - أحمد جويلي و آخرون ،"سياسات دعم الغذاء في دصر"، جامعة القاهرة، كلية الاقتصاد و العلوم

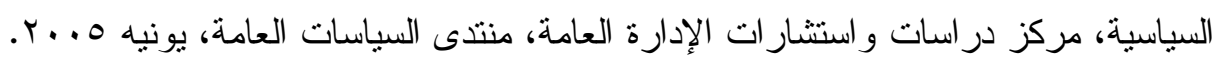
r- إمام الجمسي ، "قضية دعم الغذاء في مصر المشكلات و البدائل المطروحة لدعم الغذاء "، الجمعية

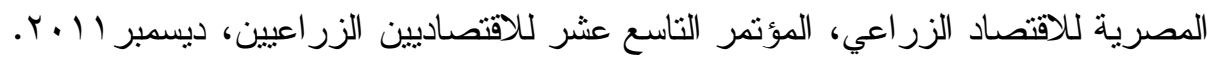

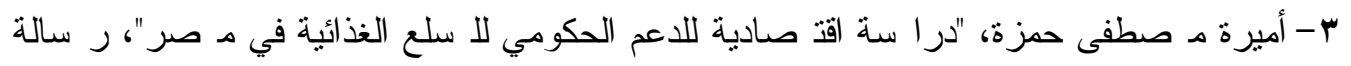
ماجستير، قسم الاقتصاد، كلية الزر اعة، جامعة طنطا، ب ا ـ ب.

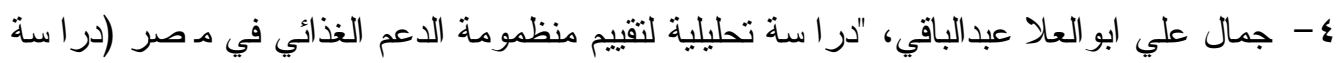
حالة بمحافظة الفيوم)" رسالة دكتور اه ، قسم الاقتصاد الزر اعي ، كلية كلية الزر اعة ، جامعة الفيوم 


$$
\begin{aligned}
& \text { ه-شوقي أمين عبدالعزيز سليم ، "در اسة اقتصادية لإنتاج وتصنيع القمح و الخبز في جمهورية مصر } \\
& \text { العربية " ، الجمعية المصرية للاقتصاد الزراعي ، المؤنمر الثاني عشر للاقتصاديين الزر اعيين، }
\end{aligned}
$$

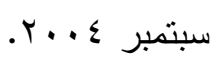

$$
\begin{aligned}
& \text { צ- شيرين فتحي محمود منصور ، "در اسة اقتصادية لأثز سياسة الدعم الغذائي على الفقر في مصر"، }
\end{aligned}
$$

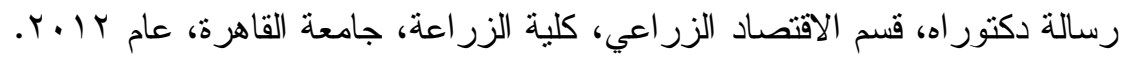

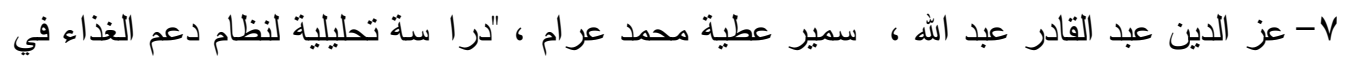

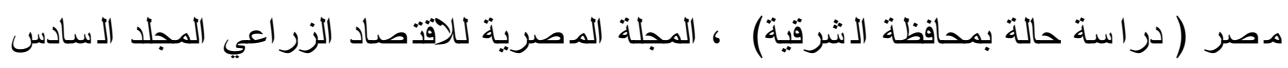

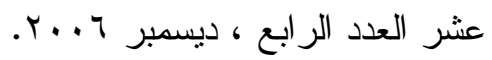

$$
\begin{aligned}
& \text { المواقع الاكترونية }
\end{aligned}
$$

